\title{
Influência do antígeno vacinal rBm 86 sobre os parâmetros biológicos da fase não-parasitária do Boophilus microplus (Canestrini, 1887)
}

\author{
Influence of vaccinal antigen $\mathrm{rBm} 86$ about biological parameters of the non- \\ parasitic stages of Boophilus microplus (Canestrini, 1887)
}

César Augusto Mora Hernández, ${ }^{\star}$ Carlos Luiz Massard, ${ }^{\star \star}$ Cleber Oliveira Soares, ${ }^{\star \star \star}$ Adivaldo Henrique da Fonseca ${ }^{\star \star \star *}$

\begin{abstract}
Resumo
O antígeno vacinal rBm 86, GAVAC ${ }^{\mathrm{TM}}$, foi avaliado contra Boophilus microplus (Canestrini, 1887) sob condições de laboratório. Foi observado em carrapatos provenientes de bovinos vacinados, comparado ao grupo controle, redução significativa no peso da teleógina $(p<0,05)$, peso da postura $(p<0,01)$ e número de ovos $(p<0,05)$. A sobrevivência larval máxima foi de 63 dias para o grupo teste contra 160 dias para o grupo controle. As alterações nos parâmetros biológicos da fase não-parasitária pode contribuir para o decréscimo da população deste carrapato nas pastagens.
\end{abstract}

Palavras-chave: vacina; biologia; Boophilus microplus.

\section{Introdução}

O desenvolvimento de resistência ou de imunidade contra o Boophilus microplus após exposição natural ou experimental, tem sido reconhecido há muitos anos por diferentes autores (Johnston e Bancroft, 1918; Trager, 1939a; Wagland, 1975). A primeira evidência de controle imunológico de carrapatos foi publicada por Trager (1939b). Este autor obteve sucesso ao vacinar cobaios com extratos brutos de Dermacentor variabilis. Nas últimas duas décadas, a produção de uma vacina eficiente contra o $B$. microplus tem merecido maior atenção por parte dos pesquisadores.

As pesquisas desenvolvidas na Austrália por Johnston et al. (1986); Kemp et al. (1986); Opdebeeck et al. (1988) e Willadsen et al. (1989), foram pioneiras em relação ao controle do $B$. microplus utilizando extratos antigênicos purificados a partir de células intestinais desta espécie. Willadsen et al. (1989) isolaram e caraterizaram a glicoproteína Bm86, a partir da superficie de membranas de células digestivas do B. microplus. Esta glicoproteína foi posteriormente adaptada em Escherichia coli(Rand et al., 1989); em Aspergilus nidulans e A. niger (Turnbull et al., 1990); em baculovirus (Richardson et al., 1993) e em Pichia pastoris (Rodriguez et al.,1994), para a obtenção do antígeno vacinal que garantiu alto nível de imunidade.
O antígeno recombinante rBm 86, desenvolve alto nível de imunidade nos bovinos, ocasionando severos danos aos carrapatos que se alimentarem em bovinos vacinados. Estes danos manifestam-se na redução do número e tamanho das fêmeas alimentadas, redução da oviposição e na fertilidade dos ovos, reduzindo o potencial reprodutivo dos carrapatos em gerações sucessivas e levando a diminuição das populações nas pastagens (Wikel, 1982; 1988; Cobon et al., 1995; Rodriguez et al., 1995).

Não foi encontrada na literatura documentação suficientemente detalhada da influência de imunógenos sobre os diferentes aspectos da biologia do B. microplus. Assim, este estudo visa avaliar os parâmetros biológicos da fase não-parasitária do $B$. microplus procedentes de bovinos imunizados com o antígeno vacinal rBm 86 - GAVAC ${ }^{\text {TM }}$.

\section{Material e métodos}

Os carrapatos foram coletados diretamente dos hospedeiros com o esquema completo de vacinação (três semanas após a $3^{\mathrm{a}}$ dose) e de animais controles, selecionando para este objetivo fêmeas ${ }^{3} 4 \mathrm{~mm}$ de comprimento. As fêmeas foram colocadas em frascos de vidro e transportadas ao laboratório, onde foram lavadas e secas em papel filtro, conforme metodologia de Stewart et al. (1982). Posteriormente, procedeu-se à pesagem individual, sendo cada fê-

\footnotetext{
*Professor Adjunto da Universidade Centroamericana, Nicarágua - Manágua.

**Departamento de Parasitologia Animal, Instituto de Biologia, UFRRJ.

${ }^{\star \star *}$ Curso de Pós-Graduação em Medicina Veterinária - Parasitologia Veterinária - UFRRJ.

****Dep. Epidemiologia e Saúde Pública, Instituto de Veterinária. Universidade Federal Rural do Rio de Janeiro. Seropédica, RJ, Brasil, $23851-970$.
} 
mea identificada e colocada em placa de petri em grupo de 20, aderidas a fita adesiva pela face dorsal do idiossoma. Após este procedimento, todos os grupos foram colocados em estufa com Umidade Relativa (UR) de $80 \pm 5 \%$ e Temperatura $28 \pm 1^{\circ} \mathrm{C}$ conforme metodologia preconizada por Davey et al. (1984). As colônias foram estabelecidas com 980 teleóginas para o grupo teste e 410 para o grupo controle, coletadas aleatoriamente. Uma vez finalizada a postura, as massas de ovos individuais foram pesadas, aliquotadas e levadas para incubadora tipo B.O.D. nas mesmas condições descritas acima.

Foram realizadas observações diárias, com o objetivo de avaliar a duração do período de pré-postura conforme metodologia descrita por Hitchcock (1955). Este período foi calculado a partir do dia da colheita até o dia do início da postura. Para determinar o período da postura, foram feitas observações diárias de cada fêmea, a partir do décimo dia de oviposição. As posturas foram separadas e pesadas, adicionando cada dia ovos encontrados até o final da oviposição. Este período foi obtido somando os dias a partir do início até o final da mesma.

Ao final da ovoposição, a massa de ovos de cada fêmea foi pesada e calculado o número de ovos conforme recomendações de Sutherst et al. (1978) e Stewart et al. (1982), tomando como parâmetro 20.000 ovos por grama.

Para expressar o índice de eficiência reprodutiva e eficiência nutricional, estes parâmetros foram calculados de acordo com a metodologia descrita por Bennett (1974a). Os resultados são expressos em dados percentuais, relacionando o peso da postura com o peso da fêmea ingurgitada correspondente, a fim de obter o índice de eficiência reprodutiva (IER). Para encontrar o índice nutricional (IEN), dividiu-se o peso da pos- tura pela diferença do peso da fêmea após a coleta e o peso residual desta ao final da postura.

O período de incubação foi considerado como aquele compreendido entre o primeiro dia de postura até o início da eclosão dos ovos, conforme estabelecido por Oliveira et al. (1974), e o período de eclosão foi consiiderado entre o primeiro e o último dia da eclosão. O cálculo do porcentual de eclosão foi realizado 10 dias após o término da mesma e estimado visualmente, conforme metodologia descrita por Davey et al. (1984). A sobrevivência das larvas de ambas colônias estudadas, foi também determinado por avaliação visual.

Para a avaliação estatística dos dados obtidos nos parâmetros biológicos, empregou-se a análise da variância (ANOVA) (Gomes, 1987).

\section{Resultados}

No referente à pré-postura, no presente estudo foi em média de 2,8 dias, com período mínimo de 2,0 e máximo de 3,0 para a colônia de fêmeas coletadas de bovinos vacinados; em relação às fêmeas da colônia controle foi em média de 3,4 dias com período mínimo de 3,0 e máximo de 4,5.

O período de ovoposição teve uma duração média de 23 dias, com períodos mínimos de 20 e máximo de 25 para a colônia controle; observando-se a média de 16 dias, com intervalos de 14 dias mínimo e 18 dias máximo para as fêmeas coletadas de bovinos vacinados. Da colônia teste, 51 teleóginas, e 11 da colônia controle não realizaram postura.

Para teleóginas teste, a produção de ovos, em média, foi de 1.734 ovos. Na colônia controle, foi em média de 2.246 ovos. A média da oviposição do grupo teste diferiu significativamente $(p<0,05)$ à do grupo controle $(T a b .1)$.

Tabela 1: Análise estatística dos parâmetros biológicos das colônias de $B$. microplus

\begin{tabular}{lccccccccc}
\hline & Pte & Ppo & Pqu & Nov & Pin & Pee & ler & len \\
\cline { 2 - 9 } FV & QM & QM & QM & QM & QM & QM & QM & QM \\
TRAM & $14179,76^{*}$ & $5045,43^{* *}$ & $398,6198^{\mathrm{NS}}$ & $1787621^{*}$ & $37,72744^{\mathrm{NS}}$ & $9,798265^{\mathrm{NS}}$ & $176,9235^{\mathrm{NS}}$ & $8,778245^{\mathrm{NS}}$ \\
RES & 1897,10 & 629,3344 & 565,2120 & 248429,5 & 55,11855 & 724,1595 & 77,29408 & 133,5553 \\
CV & 20,317 & 26,290 & 41,332 & 26,252 & 33,068 & 34,620 & 19,708 & 19,627 \\
Máximo & 380.0 & 200.0 & 320.0 & 4000.0 & 37 & 100.0 & 92.0 & 100.0 \\
Med.CV & $199,73^{\mathrm{B}}$ & $96,9^{\mathrm{B}}$ & $59,97^{\mathrm{A}}$ & $1734^{\mathrm{B}}$ & $21,7^{\mathrm{A}}$ & $78,64^{\mathrm{A}}$ & $42,97^{\mathrm{A}}$ & $63,53^{\mathrm{A}}$ & 0 \\
Mínimo & 40,0 & 0 & 10.0 & 0 & 10 & 0 & 0 & 0 \\
Máximo & 420.0 & 260.0 & 210.0 & 5200 & 40 & 100.0 & 92.8 & 100.0 \\
Med.SV & $243,70^{\mathrm{A}}$ & $112,95^{\mathrm{A}}$ & $52,6^{\mathrm{A}}$ & $2246^{\mathrm{A}}$ & $24,26^{\mathrm{A}}$ & $79,00^{\mathrm{A}}$ & $47,90^{\mathrm{A}}$ & $61,3^{\mathrm{A}}$ \\
Mínimo & 70.0 & 0 & 10.0 & 0 & 18 & 0 & 0 & 0 \\
\hline
\end{tabular}

*Significativo ao nível de $\mathrm{P}<0,05$. - ** Significativo ao nível de $\mathrm{P}<0,01$. - Médias com letras diferentes na coluna apresentam diferenças significativas. - NS Não significativo. - Pte/g. Peso da teleógina. - Ppo/g. Peso da postura. - Pqu/g. Peso da quenógina. - Nov. Número de ovos. - Pin. Período de incubação. - Pec. Período de eclosão. - ler. Índice reprodutivo. - len. Índice nutricional. - Med.CV. Média da colônia teste Med.SV. Média da colônia controle. 
Em relação à viabilidade das posturas, observou-se que a $80 \% \pm 5 \%$, ambas colônias expressaram ótimo desempenho na fertilidade, obtendo-se índices de eclosão de 78,64\% para a colônia teste e $79 \%$ para colônia controle, não diferindo significativamente à análise da variância $p>0,05$ (Tab.1). Entretanto, durante o experimento, observou-se o fato da rápida deterioração de larvas eclodidas da colônia teste, em comparação às da colônia controle.

A média do período de incubação observado foi de 21,7 dias para colônia teste, enquanto na colônia controle foi de 24,2 dias. Entretanto, o período médio de incubação para ambas colônias não diferiu significativamente $(p>0,05)$.

$A$ análise do peso das teleóginas, cuja média foi de $0,243 \mathrm{~g}$ para colônia controle e $0,199 \mathrm{~g}$ para a colônia teste, diferiu significativamente $(p<0,05)$, demonstrando portanto, que as fêmeas alimentadas sobre bovinos vacinados apresentam um comprometimento ao repasto sangüíneo, sendo, por conseguinte, altamente significativa a diferença entre os pesos das posturas de ambos grupos, ao nível de $(p<0,01)$. A percentagem de fêmeas que não conseguiram ovipositar foi mais evidente na colônia teste, em relação a controle, sendo, portanto, a média do número de ovos por postura entre as colônias significativamente diferente $(p<0,05)$.

O parâmetro do peso residual ao final da postura, o qual está intimamente relacionado ao índice de eficiência reprodutiva e ao índice de eficiência nutricional, não diferiu significativamente entre as colônias $(p>0,05)$ o que é explicável, pois, tratando-se da colônia teste, o peso residual foi maior, pelo fato da conversão do sangue ingerido em ovos ser menor devido às alterações celulares do intestino; o número de fêmeas sem postura foi maior, além do número de teleóginas analisadas neste grupo ser $42 \%$ superior ao grupo controle (Tab. 1).

As larvas da colônia teste conseguiram sobreviver em condições de laboratório até 63 dias, em contraste aos 160 dias verificados na colônia controle. Outro fato observado foi que larvas da colônia teste perdem viabilidade de infestação a partir da quinta semana de eclosão, encontrando-se mortalidade crescente a partir da sexta semana.

\section{Discussão}

O período de oviposição, aqui verificado, encontra-se dentro dos parâmetros fisiológicos normais, não se observando alterações significativas, corroborando com as observações de Bennet (1974b), o qual afirma compatibilidade da oviposição e desenvolvimento embrionário entre o limite mínimo de $15,6^{\circ} \mathrm{C}$ e máximo de $40^{\circ} \mathrm{C}$. Quanto à duração deste período, enquadra-se nas observações feitas por Alvarado e Gonzales (1979) que, trabalhando em condições idênticas às aqui detalhadas, observaram 16 dias como mínimo e 19 como máximo. Isto se deve ao fato de utilizarem carrapatos mantidos em laboratório, os quais são menos eficientes quanto ao aspecto reprodutivo (Stewart et al., 1982). Em relação à umidade relativa, não se observou influência significativa durante a oviposição, concordando com as observações de Kitaoka e Yajima (1958), os quais afirmam que a umidade tem pouco ou nenhum efeito sobre a postura.

A duração do período de postura, assim como a produção de ovos, depende da fêmea estar ou não fertilizada (Oliver Jr., 1974), havendo uma correlação linear entre o peso da teleógina e a quantidade de ovos produzidos (Kitaoka e Yajima, 1958), sendo indispensável que a fêmea ingira um volume mínimo de sangue para dar início à postura.

Os valores observados para o limite máximo de postura na colônia controle encontram-se próximo ao relatado na literatura, onde, segundo Davey et al. (1980), é de 5.466 ovos e o limite máximo de postura na colônia teste difere significativamente da colônia controle (Tab.1). Os aspectos quantitativos da oviposição de B. microplus desafiados a imunógenos não foram relatados em detalhe até o presente na literatura, sendo, portanto, esta a primeira observação da influência de uma vacina sobre a eliminação de ovos nesta espécie.

Tomando a média como parâmetro de avaliação, para o período de incubação, esta assemelha-se aos valores reportados por Hitchcock (1955) e Gonzales et al. (1975), que foram respectivamente 21-27 dias e 21-24 dias; não obstante, Bennet (1974a) assinala 29 dias de incubação, o que contrasta com essa observação, assim como as de Roveda (1954) citado por Nuñez et al. (1982), que variou entre 40-50 dias.

A curta longevidade e baixo poder de fixação das larvas da colônia teste em relação à colônia controle é de grande importância para controlar B. microplus nas pastagens. De acordo com as observações de Gonzales (1995), que afirma que as larvas têm capacidade de sobreviver por mais de 200 dias, embora não tenham capacidade de infestar o hospedeiro. Apenas, nos primeiros 90 dias, possuem vitalidade suficiente para buscar o hospedeiro e fixar-se. Nuñez et al. (1982) também relatam longevidade das larvas por 250 dias, in vitro.

Uma das possíveis explicações, no que refere a curta longevidade das larvas no presente estudo na colônia teste, reside no fato de que aproximadadmente $5-10 \%$ da partícula heme ingerida passa para o desenvolvimento dos oócitos (Kitaoka, 1961). O complexo heme dos ovos é uma proteína diferente da hemoglobina do hospedeiro. Logo depois da quebra da hemoglobina, algumas partes de ferro e heme passam à hemolinfa, ligando-se a proteínas específicas do carrapato. Este novo tipo de composto, ferroproteína, é denominado de hemixodovina (Bremner, 1959). A função da hemixodovina aparentemente é de reserva protéica durante a embriogênese, e de reserva energética nas larvas em jejum (Balashov, 1972).

A outra possibilidade reside no fato de que, após o desprendimento das fêmeas ingurgitadas do hospedeiro, o retículo endoplasmático rugoso das células intestinais 
começa a reorganizar-se, sintetizando grânulos, o que corrobora o efeito dos componentes séricos sobre as células digestivas das teleóginas, e o conseqüente efeito na oviposição (Coons et al., 1982; Agbede e Kemp, 1986). O material secretado por estas células do $B$. microplus se faz nos espaços extracelulares das dobras basais, que estão em contato com a hemolinfa (Agbede e Kemp, 1987). Desta forma, pode ser relacionado o curto período de sobrevivência nas larvas de $B$. microplus de primeira geração, descendentes de fêmeas, procedentes de bovinos vacinados com o antígeno vacinal $\mathrm{rBm} 86$. Conseqüentemente, este fato poderia explicar a redução acentuada de larvas no pasto e o poder de fixação sobre os animais vacinados.

A redução na população desta espécie de carrapato acontece pelo fato de alterar os processos biológicos, especialmente o processo metabólico da digestão, afetando gerações que se sucedem. Conseqüentemente, a reprodução torna-se menos eficiente e a capacidade de sobrevivência das larvas diminui substancialmente. As alterações nos parâmetros biológicos da fase não-parasitária do $B$. microplus é mais um fato que contribui para a redução da população deste carrapato nas pastagens.

\section{Abstract}

The vaccinal antigen rBm 86, GAVACä, was evaluated against Boophilus microplus (Canestrini, 1887) under laboratory conditions. Reductions in: engorged female tick weight, $(p<0.05)$, egg mass weight $(p<0.01)$, egg number $(p<0.05)$, were observed in $B$. microplus, surviving from vaccined compared to control cattle. Maximum larval survival was 63 days in ticks from vaccinated cattle and 160 days from controls. Alterations in such biological parameters can contribute to decreases in populations of this tick species in the pasture.

Keywords: tick vaccine; cattle tick biology; Boophilus microplus.

\section{Referências bibliográficas}

AGBEDE, R. I. S., KEMP, D. H. Immunization of cattle against Boophilus microplus using extracts derived from adult female ticks: histopathology of ticks feeding on vaccinated cattle. Internat. J. Parasitol., v. 16, n. 1, p. 35-41, 1986.

AGBEDE, R. I. S., KEMP, D. H. Ultrastructure of secretory cells in the gut of the cattle-tick Boophilus microplus. Internat. J. Parasitol., v. 17, n. 6, p.1089-1098, 1987.

ALVARADO, R. U., GONZALES, J. C. A postura e a viabilidade do Boophilus microplus (Canestrini, 1887) (Acarina, Ixodidae) em condições de laboratório. Rev. Latinoam. Microbiol., v. 21, p. 31-36, 1979.

BALASHOV, Y. S. Bloodsucking ticks (Ixodoidea) vector of diseases of man and animals. Misc. Publicat. Entomol. Soc. Am., v. 8, n. 5, p. 159-376, 1972.

BENNET, G. F. Oviposition of Boophilus microplus (Canestrini) (Acarida: Ixodidae) I. Influence of tick on egg production. Acarologia, T. XVI, Fasc.1, p. 52-61, 1974a.

BENNET, G. F., Oviposition of Boophilus microplus (Canestrini) (Acarida: Ixodidae). II. Influence of temperature, humidity and light. Acarologia, T. XVII, Fasc. 2, p. 250-257, 1974 b.

BREMNER, K. C. Studies on "haemoxidovin", the pigments in the eggs of the cattle tick Boophilus microplus (Acarina, Ixodidae). Aust. J. Biol. Sci., v.12, p. 263-273, 1959.

COBON, G., HUNGERFORD, J., WOODROW, M., SMITH, D., WILLADSEN, P. Vaccination against Boophilus microplus: Australian field experience. In: DE LA FUENTE, J. (Ed.) Reconbinant vaccines for the control of cattle tick, Elfos Scientiae, p. 163-176, 1995.

COONS, L. B., TARNOWSKI, B., QURTH, D. D. Rhipicephalus sanguineus: Localization of vitelogenin synthesis by immunological methods and eletron microscpy. Experim. Parasitol., v. 54, p. 331-339, 1982.
DAVEY, R. B., GARZA, J., THOMPSON, G. D., DRUMMOND, R. $O$. Ovipositional biology of the southern cattle tick, Boophilus microplus (Acari: Ixodidae), in the laboratory. J. Med. Entomol., v. 17, n. 2, p.117-121, 1980.

DAVEY, R. B., OSBURN, R. L., MILLER, J. A. Ovipositional and morphological comparisons of Boophilus microplus (Acari: Ixodidae) collected from different geografical areas. Ann. Entomol. Soc Am., v. 77, n. 1, p.1-5, 1984.

GOMES, F. P. Curso de estatística experimental 12. ed. Livraria Novel, 467 p., 1987.

GONZALES, J. C., SILVA, N. R., FRANCO, N., PEREIRA, I. H. O. A vida livre do Boophilus microplus (Can. 1887). Arq. Fac. Vet. Univ. Fed. Rio Grande do Sul, v. 3, n. 1, p. 21-28, 1975.

GONZALES, J. C. O controle do carrapato do boi. 2. ed. Porto Alegre, RS. 80 p. 1995.

HITCHCOCK, I. F. Studies on the non-parasitic stages of the cattle tick, Boophilus microplus (Canestrini). Aust. J. Zool., v. 3, p. 295-311, 1955.

JOHSNTON, T. H., BANCROFT, M. J. A tick resistant condition in cattle. Proc. Royal Soc. Queensland., v. 41, p. 121-132, 1918.

JOHSTON, L. A. Y., KEMP, D. H., PEARSON, R. D. Immunization of cattle against Boophilus microplus using extracts derived from adult female ticks: Effects of induced immunity on tick populations. Internat. J. Parasitol., v. 16, p. 27-34, 1986.

KEMP, D. H., AGBEDE, R. I. S., JOHNSTON, L. A. Y., COUGH, J. $M$. Immunization of cattle against Boophilus microplus using extracts derived from adult female ticks: feeding and survival of the parasite on vaccinated cattle. Internat. J. Parasitol., v. 16, p. 115-120, 1986.

KITAOKA, S., YAJIMA, A. Physiological and ecological studies on some ticks. II. Phase change of ovipositing ability with blood-sucking quantity. Bull. Natio. Inst. Ani. Hth., v. 34, p. 149-162, 1958. 
KITAOKA, S. Physiological and ecological studies on somes ticks VI. Rate of digestion of blood-meal and nitrogen, iron and, sterol economy in the tick. Bull. Naio. Inst. Ani. Hth., v. 1, p. 105-112, 1961.

NUÑEZ, J. L., MUÑOZ, C. M. E., MOLTEDO, H. L. Boophilus microplus. la garrapata común del ganado vacuno. Edit. Hemisferio Sur. Buenos Aires. 184 p. 1982.

OLIVER Jr, J. H. IV Reproduction in ticks. In: Symposium on reproduction of arthropods on medical and veterinary importance. J. Med. Entomol., v. 11, p. 26-34, 1974.

OLIVEIRA, G. P., COSTA, R. P., MELLO, R. P., MENEGUELLI, C. A. Estudo ecológico da fase não-parasítária do Boophilus microplus (Canestrini, 1887) (Acarina, Ixodidae) no Estado do Rio de Janeiro. Arq. Univ. Fed. Rur. do Rio de Janeiro, v. 4, n. 1, p. 1-10, 1974.

OPDEBEECK, J. P., WONG, J. Y.M., JACKSON, L. A., DOBSON, C. Vaccine to protect hereford cattle tick, Boophilus microplus. Immunology, v. 63, p. 363-367, 1988.

RAND, K. N., MOORE, T., SRISKANTHA, A., SPRING, K., TELLAN, R., WILLADSEN, P., COBON, G. S. Cloning and expression of a protective antigen from the cattle tick Boophilus microplus. Proc. Natio. Acad. Sci. USA. Biochemistry, v. 86, p. 9657-9661, 1989.

RICHARDSON, M. A., SMITH, D. R. J., KEMP, D. H., TELLAN, R. L. Native and baculovirus-expressed forms of the immunoprotective protein $\mathrm{Bm} 86$ from Boophilus microplus are anchored to the cell membrane by a glycosylphosphatidyl inositol linkage. Ins. Mol. Biol., v. 1, p. 1-9, 1993.

RODRÍGUEZ, M., RUBIERA, R., PENICHET, M., MONTESINOS, R., CREMATA, J., FALCON, V. I., SÁNCHEZ, G., BRINGAS, R., CORDOVÉS, C., VALDÉS, M., LLEONART, R., HERRERA, L., DE LA FUENTE, J. High level expression of the $B$. microplus Bm 86 antigen in the yeast Pichia Pastoris forming highly immunogenic particles for cattle. J. Biotechnol., v. 33, p. 135-146, 1994.
RODRÍGUEZ, M., MASSARD, C. L., FONSECA, A. H., RAMOS, N. F., MACHADO, H., LABARTA, V., DE LA FUENTE, J. Effect of vaccination with a recombinant $\mathrm{Bm} 86$ antigen preparation on natural infestation of Boophilus microplus in grazing dairy and beef pure and cross breed cattle in Brazil. Vaccine, v. 13, n. 18, p. 1804-1808, 1995.

STEWART, N. P., CALLOW, L. L., DUNCALFE, F. Biological comparisons between a laboratory - mantained and recently isolated field strain of Boophilus microplus. J. Parasitol., v. 68, n. 4, p. 691-694, 1982.

SUTHERST, R. W., WHARTON, R. H., UTECH, K. B. W. Guide to studies on tick ecology. C.S.I.R.O. Aust. Divis. Entomol. Techn. Pap., v. 14, p. 1-59, 1978.

TRAGER, W. Acquired immunity to ticks. J. Parasitol., v. 25, p. 57-81, 1939a.

TRAGER, W. Further observations on acquired immunity to the tick Dermacentor variabilis Say. J. Parasitol., v. 25, p. 137139, $1939 b$.

TURNBULL, I. F., SMITH, D. R. J., SHARP, P. J., COBON, G. S., HYNES, M. J. Expression and secretion in Aspregillus nidulans and $A$. niger: of a cell surface glycoprotein from the cattle tick, Boophilus microplus, by using the fungal and $\mathbf{S}$ promoter system. Appl. Envirom. Microbiol., v. 56, n. 9, 28472852, 1990.

WAGLAND, B. M. Host resistance to cattle tick (Boophilus microplus) in brahman (Bos Indicus) cattle. I. Reponses of previous by uninfected cattle to four infestations with 20000 larvae. Aust. J. Agric. Res., v. 26, p. 1073-1080, 1975.

WIKEL, S. K. Immune responses to arthropods and their products. Ann. Rev. Entomol., v. 27, p. 21-48, 1982.

WILLADSEN, P., RIDING, G. A., MCKENNA, R. V., KEMP, D. H., TELLAM, R. L., NIELSEN, J. N., LAHNSTEIN, J., COBON, G. S., GOUGH, J. M. Immunologic control of a parasitic arthropod, identification of a protective antigen from Boophilus microplus. J. Immunol., v. 143, n. 4, p. 1346-1351, 1989.

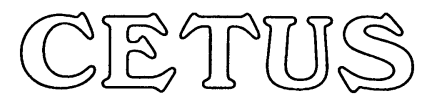

NIKON (Japão)

Distribuidor Nacional

Cetus Hospitalar Comércio e Representações Ltda.

Microscópios Biológicos e Industriais - Espectofotômetros Deonizadores - Kits para bioquímica - Contador de Células Assistência Técnica

Rua Lopes Trovão, 75 - Benfica 20920-310 - Rio de Janeiro - RJ Tel.: (021) 568-9345 Fax: (021) 264-3628

E-mail: cetus@abeunet.com.br 